\title{
Different Carbon Nanostructured Materials Obtained in Catalytic Chemical Vapor Deposition
}

\author{
Carla Veríssimo, ${ }^{a}$ Stanislav A. Moshkalyov, ${ }^{*, a}$ Antônio C. S. Ramos, ${ }^{b}$ José L. Gonçalves, ${ }^{a}$ \\ Oswaldo L. Alves ${ }^{c}$ and Jacobus W. Swart ${ }^{a}$ \\ ${ }^{a}$ Centro de Componentes Semicondutores, Universidade Estadual de Campinas, CP 6061, 13083-970 \\ Campinas-SP, Brazil \\ ${ }^{b}$ Instituto de Física “Gleb Wataghin”, 13083-970 Campinas-SP, Brazil \\ 'Instituto de Química, Universidade Estadual de Campinas, CP 6154, 13083-970 Campinas-SP, Brazil
}

\begin{abstract}
Diferentes materiais nanoestruturados à base de carbono, tais como nanotubos, nanofibras, nanomolas e nanooctopus, foram obtidos através do processo de deposição química de vapor. Tais experimentos foram realizados em um forno tubular e variações nos parâmetros experimentais permitiram a obtenção das diferentes nanoestruturas de carbono. Filmes finos de $\mathrm{Ni}$ e $\mathrm{Cu}$ foram depositados sobre substratos de $\mathrm{SiO}_{2} / \mathrm{Si}$ e empregados como catalisadores. $\mathrm{O}$ efeito de diferentes gases precursores de carbono, da temperatura de crescimento e do metal catalítico sobre as características do material final foi investigado por microscopia eletrônica de varredura, espectroscopia Raman e difratometria de raios $\mathrm{X}$ com ângulo rasante. $\mathrm{O}$ uso dos gases metano $\mathrm{e}$ acetileno levaram à formação de nanotubos de carbono para ambos os filmes metálicos, enquanto $\mathrm{Ni}$ parcialmente oxidado promoveu o crescimento de nanomolas. Estruturas do tipo octopus foram obtidas a partir do uso de cobre associado a um fornecimento relativamente restrito de metano.
\end{abstract}

Different carbon nanostructured materials, such as nanotubes, nanofibers, nanosprings and nanooctopus, were grown by changing the metal catalyst and experimental parameters of the thermal chemical vapor deposition process. These experiments were performed using a tubular furnace and methane or acetylene as carbon feedstock gases. Thin films of $\mathrm{Ni}$ or $\mathrm{Cu}$ were deposited onto a $\mathrm{SiO}_{2} / \mathrm{Si}$ substrate and employed as catalysts. The effect of the growth temperature, metal catalyst and carbon gas precursor (methane or acetylene) on the final carbon nanoestructured material was studied by scanning electron microscopy, Raman spectroscopy and grazing incidence X-ray diffraction. Growth of multiwall carbon nanotubes (MWCNTs) was observed using both metal films and carbon precursor gases, whereas partially oxidized Ni films promoted formation of nanosprings. Experiments with reduced supply of methane resulted in octopus-like carbon nanostructures when a $\mathrm{Cu}$ film was used as a catalyst.

Keywords: carbon nanotubes, carbon nanosprings, carbon nanooctopus, Chemical Vapor Deposition (CVD), metal catalysis

\section{Introduction}

The ability of carbon to form strong chemical bonds with itself (in different allotropic forms) and many other elements is responsible for the existence of a vast number of carbon-based materials and compounds. It makes carbon one of the most fascinating building blocks for synthesis of new structures with unique properties. As a consequence, a great variety of carbon nanostructured materials have been grown in many

*e-mail: stanisla@led.unicamp.br laboratories. ${ }^{1-14}$ Among the different carbon nanostructures, nanotubes (CNTs) have received much attention due to their extraordinary electronic, mechanical, chemical, optical and other properties. ${ }^{1}$ Depending on their structural characteristics, CNTs can exhibit metallic or semiconductor behavior, thus being promising material for designing new nanoelectronic devices, such as field-effect transistors. ${ }^{1,2}$ Many other potential technological applications can be listed, such as scanning probe microscope tips, molecular computing elements, field-emission displays and sensors. ${ }^{1}$ The development of technologies involving 
carbon nanotubes and other nanostructures can result in nano-devices characterized by high performance, low mass and low consumption of energy. However, many issues have to be addressed (e.g., the lack of precise control in formation of a desired carbon nanostructure) for the successful development of technologies based on carbon nanostructured materials.

Among the several methods that have been used for the growth of CNTs, thermal CVD is shown to be an efficient and versatile technique for the nanotubes synthesis. ${ }^{3-6}$ The growth of carbon nanostructures by thermal CVD employs a carbon precursor molecule and a transition metal as a catalyst. Since this procedure is performed at relatively low temperatures (lower than $1000{ }^{\circ} \mathrm{C}$ ) as compared with other techniques, it becomes even more attractive, being compatible with other technologies involved in the preparation of electronic devices.

By changing the experimental conditions in catalytic CVD, CNTs presenting significant structural differences such as straight, curved or helical shapes, can be obtained. ${ }^{1,7,8}$ In addition, other carbon nanostructured materials, including carbon polyhedra, graphite onions, carbon nanohorns and carbon nanospheres have also been reported as well as carbon nanofibers and nanosprings. ${ }^{7,9,10}$ These non-straight carbon nanostructures could also have interesting properties. For example, mechanical properties of carbon nanosprings are under investigation and the results revealed an elastic spring behaviour. ${ }^{11}$ Carbon nanosprings may not only possess interesting mechanical properties, but could also show an electromagnetic inductive effect to generate a magnetic field through the conduction of electricity, as suggested by Huang and Dai. ${ }^{7}$ Another unusual nanostructure called octopus-like carbon or carbon nanooctopus has been observed in a few studies. Such nanostructured material is obtained from a multidirectional or branched growth with several carbon filaments grown from a single catalyst particle. ${ }^{12,13} \mathrm{~A}$ significant number of different morphologies can be observed for carbon nanomaterials and a lot of research has been dedicated to the understanding of the factors that influence the formation of this specific carbon nanostructure. ${ }^{7,8-14}$

Focusing on CVD method, there are numerous experimental parameters that can be adjusted during the synthesis process, and the identification and control of the critical parameters is crucial for the development and optimization of the synthesis process, study of growth models and, eventually, nano-devices fabrication. Thus, the analysis of the effect of experimental conditions such as temperature of growth, carbon precursor molecule and catalyst, among others, is very important.

In this work, the effect of different transition metals as a catalyst on the thermal CDV growth of carbon nanostructures, using methane or acetylene as carbon precursors, was studied. The influence of growth temperature and the precursor concentration was also evaluated. It has been demonstrated that apparently small changes in experimental conditions can result in dramatic changes in the stucture of the grown nanocarbon materials.

\section{Experimental}

Thin catalyst films were deposited onto silicon wafers covered by a $50 \mathrm{~nm}$ thick thermally grown silicon oxide layer. Electron beam evaporation and plasma sputtering techniques were used for deposition of $\mathrm{Ni}(6$ and $12 \mathrm{~nm})$ and $\mathrm{Cu}(3,5$ and $20 \mathrm{~nm})$ metal films, respectively. Further, the silicon wafers coated by metal films were cut in small pieces $\left(5 \times 5 \mathrm{~mm}^{2}\right)$ and annealed in a quartz tube furnace at $700{ }^{\circ} \mathrm{C}$ in a $\mathrm{H}_{2}$ flow of $400 \mathrm{sccm}$ during 30 minutes. After the annealing process, four different CVD processes were used to obtain carbon nanostructured materials.

\section{Growth method 1}

The hydrogen was replaced by $\mathrm{NH}_{3}$ flow of $400 \mathrm{sccm}$ during 5 minutes. Then, the temperature was raised to $800-950{ }^{\circ} \mathrm{C}$, and the synthesis was started by addition of 25-100 sccm of $\mathrm{CH}_{4}$ for 30 minutes. After the first 5 minutes of the synthesis, $\mathrm{NH}_{3}$ was replaced by the same flow of $\mathrm{H}_{2}$. During the main growth phase, the $\mathrm{H}_{2}: \mathrm{CH}_{4}$ gas ratios were $4: 1,8: 1$ or $16: 1$.

\section{Growth method 2}

The flow of $\mathrm{H}_{2}$ was decreased to $100 \mathrm{sccm}$ and the temperature was raised to $950{ }^{\circ} \mathrm{C}$. The synthesis was started by addition of $7 \mathrm{sccm}$ of $\mathrm{CH}_{4}$ for 30 minutes.

\section{Growth method 3}

The temperature was raised to $800{ }^{\circ} \mathrm{C}$ and a flow of 50 sccm of $\mathrm{C}_{2} \mathrm{H}_{2}$ was introduced for 30 minutes, keeping the $\mathrm{H}_{2}$ flow of $400 \mathrm{sccm}$.

\section{Growth method 4}

The flow of $\mathrm{H}_{2}$ was increased to $600 \mathrm{sccm}$ after the 
annealing, and a flow of $6 \mathrm{sccm}$ of $\mathrm{C}_{2} \mathrm{H}_{2}$ was introduced for 15 minutes keeping the temperature at $700{ }^{\circ} \mathrm{C}$.

A high resolution scanning electron microscope FEGSEM JSM 6330F was used for structural analysis of samples. Raman spectroscopy was performed employing a Renishaw System 3000 Raman Imaging Microscope, using the $632.8 \mathrm{~nm}$ line of a He-Ne laser. Grazing

Table 1. Experimental parameters for samples prepared by the growth method 1 using either $6 \mathrm{~nm}$ thick $\mathrm{Ni}$ film or $3 \mathrm{~nm}$ thick $\mathrm{Cu}$ film

\begin{tabular}{lccc}
\hline $\begin{array}{l}\text { Ni Film } \\
(6 \text { nm thick })\end{array}$ & $\begin{array}{c}\text { Cu Film } \\
(3 \mathrm{~nm} \text { thick })\end{array}$ & $\begin{array}{c}\text { Growth } \\
\text { Temperature }\end{array}$ & $\begin{array}{c}\mathrm{H}_{2}: \mathrm{CH}_{4} \\
\text { Gas Ratio }\end{array}$ \\
\hline Ni-850/4 & $\mathrm{Cu}-850 / 4$ & $850^{\circ} \mathrm{C}$ & $4: 1$ \\
Ni-850/8 & $\mathrm{Cu}-850 / 8$ & $850^{\circ} \mathrm{C}$ & $8: 1$ \\
Ni-850/16 & $\mathrm{Cu}-850 / 16$ & $8500^{\circ} \mathrm{C}$ & $16: 1$ \\
Ni-900/4 & $\mathrm{Cu}-900 / 4$ & $900{ }^{\circ} \mathrm{C}$ & $4: 1$ \\
Ni-900/8 & $\mathrm{Cu}-900 / 8$ & $900^{\circ} \mathrm{C}$ & $8: 1$ \\
Ni-900/16 & $\mathrm{Cu}-900 / 16$ & $900{ }^{\circ} \mathrm{C}$ & $16: 1$ \\
Ni-950/4 & $\mathrm{Cu}-950 / 4$ & $950{ }^{\circ} \mathrm{C}$ & $4: 1$ \\
Ni-950/8 & $\mathrm{Cu}-950 / 8$ & $950{ }^{\circ} \mathrm{C}$ & $8: 1$ \\
Ni-950/16 & $\mathrm{Cu}-950 / 16$ & $950{ }^{\circ} \mathrm{C}$ & $16: 1$ \\
\hline
\end{tabular}
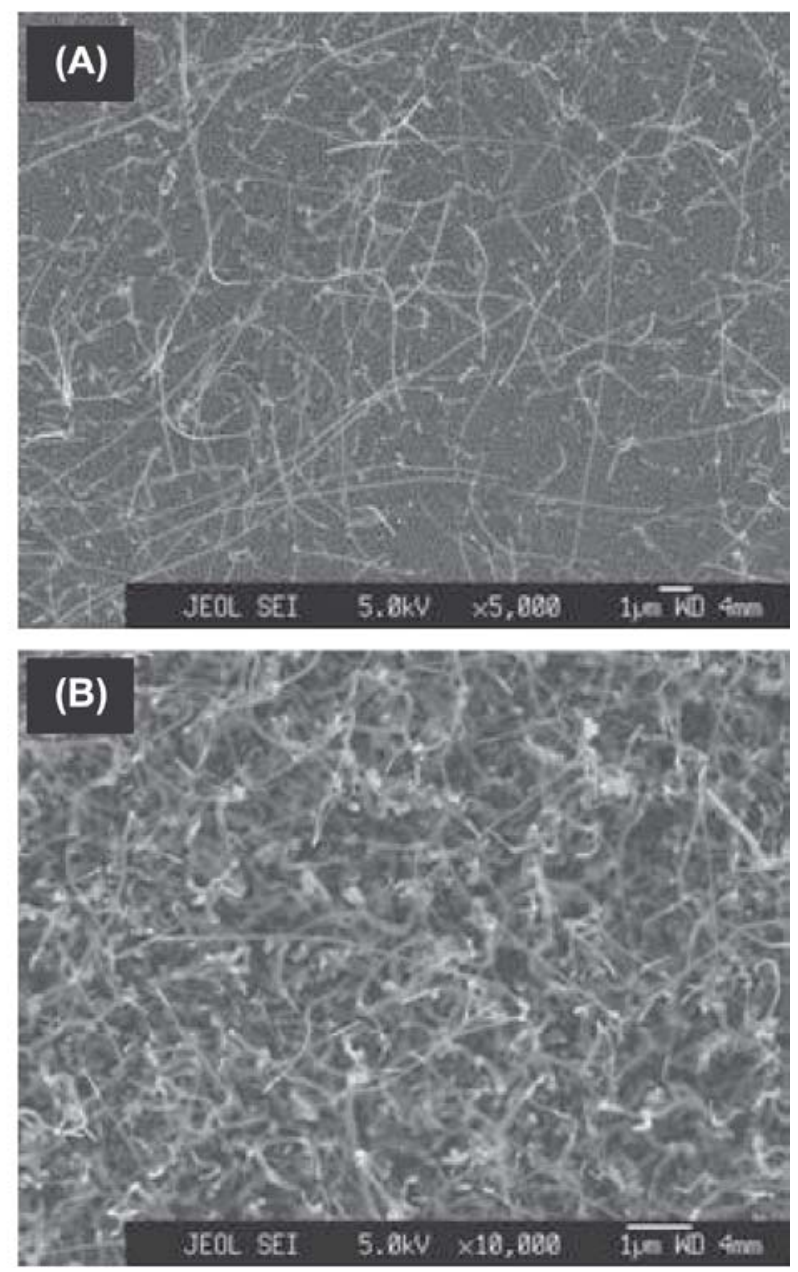

Figure 1. SEM images of samples prepared by growth method 1 using $\mathrm{Ni}$ film at $950{ }^{\circ} \mathrm{C}$ and different $\mathrm{H}_{2}: \mathrm{CH}_{4}$ ratios: (A) 16:1 and (B) 4:1. incidence X-ray diffraction (GIXRD) measurements were performed in the X-ray diffraction beamline of the Brazilian Synchrotron Light Laboratory (LNLS) by using an incidence angle of $1.5^{\circ}(\lambda=1.54 \AA)$.

\section{Results and Discussion}

Carbon nanotubes were obtained with different methane concentrations, growth temperatures and metal catalysts by using the growth method 1 . Table 1 presents a description of experimental conditions for samples prepared with $\mathrm{Ni}(6 \mathrm{~nm})$ or $\mathrm{Cu}(3 \mathrm{~nm})$ catalyst films.

The effect of the methane concentration on the CNT growth with $\mathrm{Ni}$ catalyst appears to depend essentially on the process temperature. In experiments at temperatures of 850,900 and $950{ }^{\circ} \mathrm{C}$, higher concentration of methane during the growth process resulted in a higher CNT density (Figure 1) indicating that the growth process is apparently limited by carbon supply. At $850^{\circ} \mathrm{C}$, CNTs were not formed for the most diluted $\mathrm{H}_{2}: \mathrm{CH}_{4}$ mixture. Furthermore, the formation of CNTs was not observed at the lower temperature (800 ${ }^{\circ} \mathrm{C}$ ), independently on the methane concentration.

The length of CNTs was also sensitive to the growth experimental parameters. For example, in the sample $\mathrm{Ni}-850 / 8$ CNTs length reached $2 \mu \mathrm{m}$ whereas in the sample Ni-850/4 (Table 1) nanotubes up to $4 \mu \mathrm{m}$ long were observed. In the case of samples Ni-900/16 and $\mathrm{Ni}-900 / 4$ (Table 1), nanotubes as long as 4 and $10 \mu \mathrm{m}$, respectively, were obtained. As a general trend, higher temperatures and methane concentrations resulted in longer carbon nanotubes. These results indicate a carbon supply limited growth and enhancement of the nickel catalytic capability with temperature.

The chemical state of the nickel catalyst was investigated by grazing incident $\mathrm{X}$-ray diffraction. Figure 2A shows a XRD pattern of metallic Ni presenting a face-centered cubic lattice (fcc). The peaks centered at $44.38,51.72$ and $76.16^{\circ}(2 \theta)$ are related to (111), (200) and (220) planes. ${ }^{15}$ Figures $2 \mathrm{~B}$ and C show GIXRD patterns for Ni film with $6 \mathrm{~nm}$ of thickness thermally treated in hydrogen flow of $400 \mathrm{sccm}$ for 30 minutes at 700 and $900{ }^{\circ} \mathrm{C}$, respectively, which demonstrate the formation of metallic nickel with fcc structure after the thermal treatment. The broad peak around $56^{\circ}$ is related to the $\mathrm{Si}$ substrate. GIXRD patterns for samples Ni-850/4, Ni-900/4 and Ni-950/4 (Table 1) are presented in Figures $2 D, E$ and $F$. The preservation of the fcc nickel phase after heating at temperatures ranging from 850 to $950^{\circ} \mathrm{C}$ in the presence of a carbon precursor during the growth process was 
observed. In spite of the chemical state of catalytic metallic nickel remaining apparently unchanged in the presence of carbon at different temperatures, the results indicate the decrease of the catalytic capability of the metal with the process temperature reduction where methane was used as carbon feedstock gas.

The diameters of CNTs ranged from 20 to $100 \mathrm{~nm}$, which is characteristic of multiwalled carbon nanotubes. The characteristic profile of Raman spectra indicates the formation of MWCNTs (Figure 3). As expected, the Raman spectrum of MWCNTs is similar to that of the polycrystalline graphite, since carbon nanotubes are constituted by graphene cylindrical walls. Therefore, spectra shown in Figure 3 consist of two bands, a G-line at $1579 \mathrm{~cm}^{-1}$ associated to a crystalline graphitic structure and a D-line near $1330 \mathrm{~cm}^{-1}$ accompanied by a D' band at $1612 \mathrm{~cm}^{-1}$ related to a disordered graphitic structure. ${ }^{16}$ The ratio of the $\mathrm{D}$ - and G-lines intensities $\left(\mathrm{I}_{\mathrm{D}} / \mathrm{I}_{\mathrm{G}}\right)$ is used to characterize the defects in carbon nanotubes. Higher $\mathrm{I}_{\mathrm{D}} / \mathrm{I}_{\mathrm{G}}$ ratio indicate more structural defects in CNTs. As expected, sample prepared at a lower temperature $\left(850{ }^{\circ} \mathrm{C}\right.$, Figure $\left.3 \mathrm{~A}\right)$ presented the highest $\mathrm{I}_{\mathrm{D}} / \mathrm{I}_{\mathrm{G}}$ ratio $(0.75)$, since lower temperatures apparently do not lead to a high graphitization of the carbon walls structure. However, the smallest $\mathrm{I}_{\mathrm{D}} / \mathrm{I}_{\mathrm{G}}$ ratio $(0.52)$ was observed for the sample prepared at $900{ }^{\circ} \mathrm{C}$ whereas the $\mathrm{I}_{\mathrm{D}} / \mathrm{I}_{\mathrm{G}}$ ratio for the sample prepared at $950{ }^{\circ} \mathrm{C}$ was slightly higher (0.65). It is possible that due to relatively low thermal stability of methane, experiments at temperatures as high as $950{ }^{\circ} \mathrm{C}$ could result in strong thermal decomposition of the gas and deposition of different amorphous carbon materials onto the substrate, intervening in the Raman spectrum of the CNTs.

Growth method 1 showed relatively low efficiency of carbon nanotube synthesis using $\mathrm{Cu}$ as catalyst, with the length of CNTs grown being about an order of magnitude shorter than those grown with $\mathrm{Ni}$ catalyst. The best experimental condition was reached at $900{ }^{\circ} \mathrm{C}$ and higher methane concentration led to a higher CNT nucleation density (Figure 4).

While some applications may require a low density CNT nucleation (as observed in experiments with methane), in many cases higher CNTs densities is necessary. In striking contrast to the case of methane as a carbon feedstock gas, experiments performed with acetylene (growth methods 3 and 4 ) led to a high density of CNTs grown over the entire substrate. Due to higher reactivity of acetylene compared to methane, ${ }^{17}$ essentially softened experimental conditions - such as lower growth temperature $\left(700{ }^{\circ} \mathrm{C}\right)$ and carbon supply

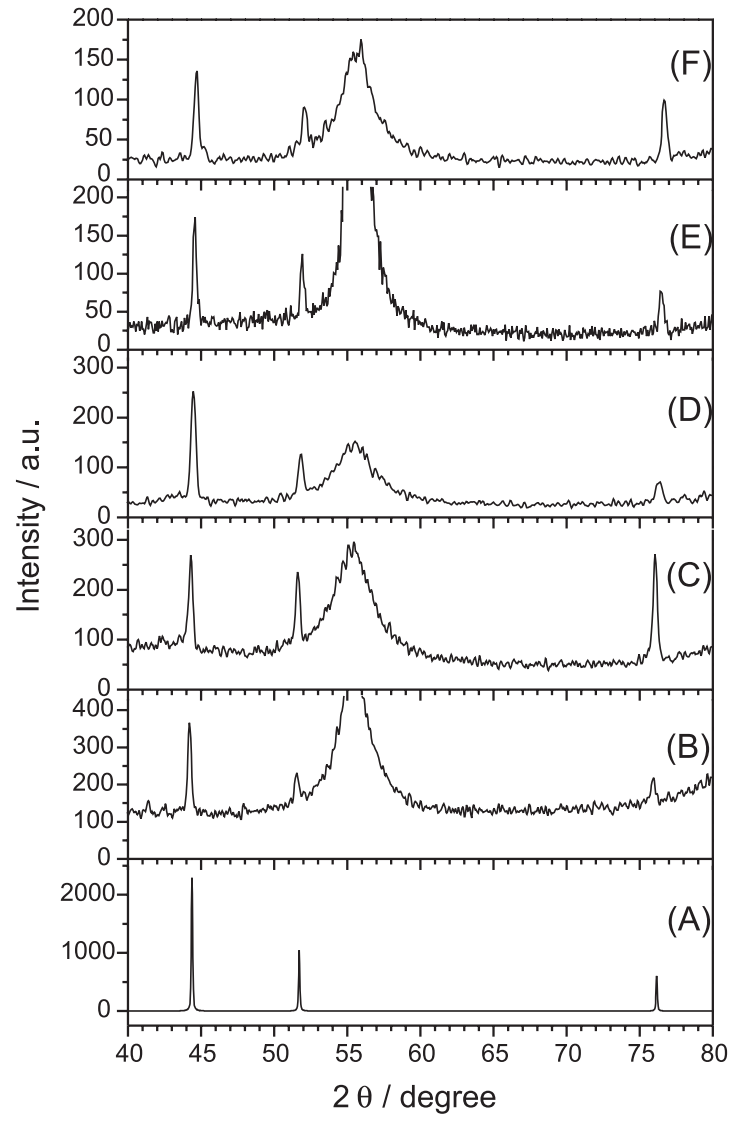

Figure 2. XRD pattern of fcc metallic nickel (A). GIXRD pattern of $6 \mathrm{~nm}$ thick Ni film heated at $700{ }^{\circ} \mathrm{C}$ (B) and $900{ }^{\circ} \mathrm{C}$ (C). GIXRD pattern of samples prepared by growth method 1 using $6 \mathrm{~nm}$ thick Ni film, $\mathrm{H}_{2}: \mathrm{CH}_{4}$ ratios $=4: 1$ and temperatures of $850(\mathrm{D}), 900(\mathrm{E})$ and $950{ }^{\circ} \mathrm{C}(\mathrm{F})$.

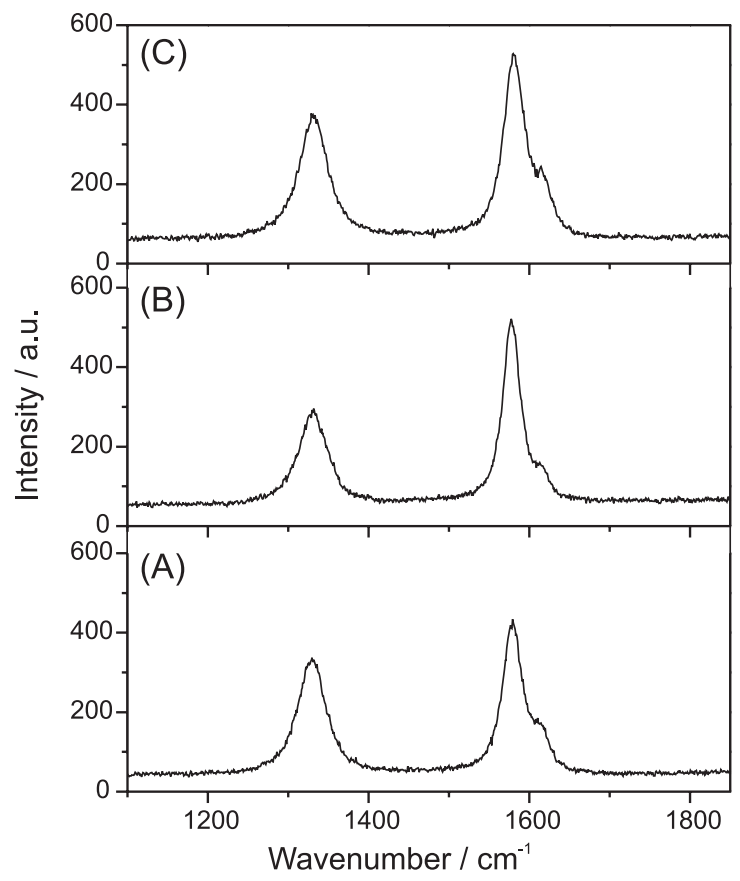

Figure 3. Raman spectra of CNTs grown by growth method 1 using a gas ratio of $\mathrm{H}_{2} / \mathrm{CH}_{4}=4: 1$ at different temperatures: (A) $850{ }^{\circ} \mathrm{C}$, (B) $900{ }^{\circ} \mathrm{C}$, and (C) $950^{\circ} \mathrm{C}$. 


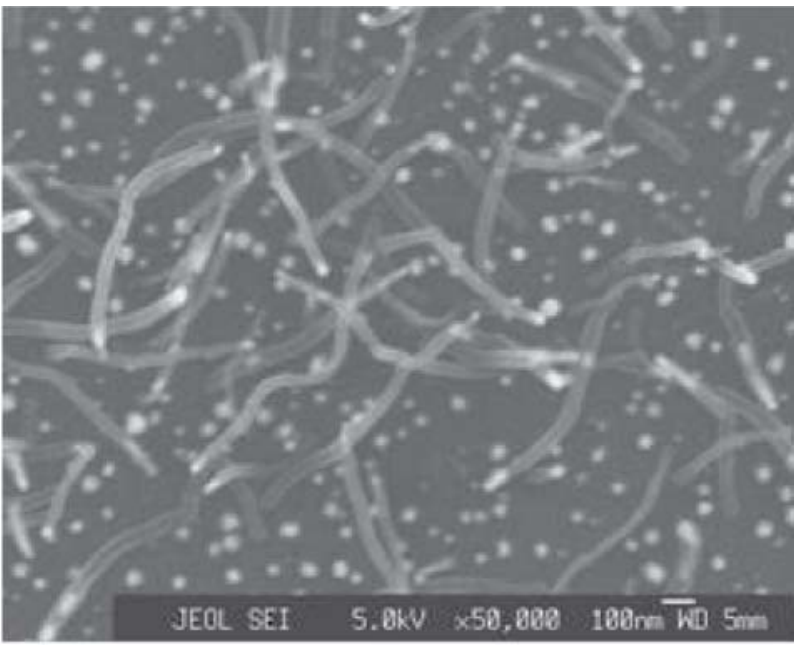

Figure 4. SEM image of sample prepared by growth method 1 using $\mathrm{Cu}$ film at $900{ }^{\circ} \mathrm{C}$ and $\mathrm{H}_{2}: \mathrm{CH}_{4}$ ratio of $4: 1$.

$\left(\mathrm{H}_{2}: \mathrm{C}_{2} \mathrm{H}_{2}=100: 1\right)$ - also resulted in an intense CNT growth (Figure 5). The enhanced acetylene reactivity apparently makes the whole growth process less
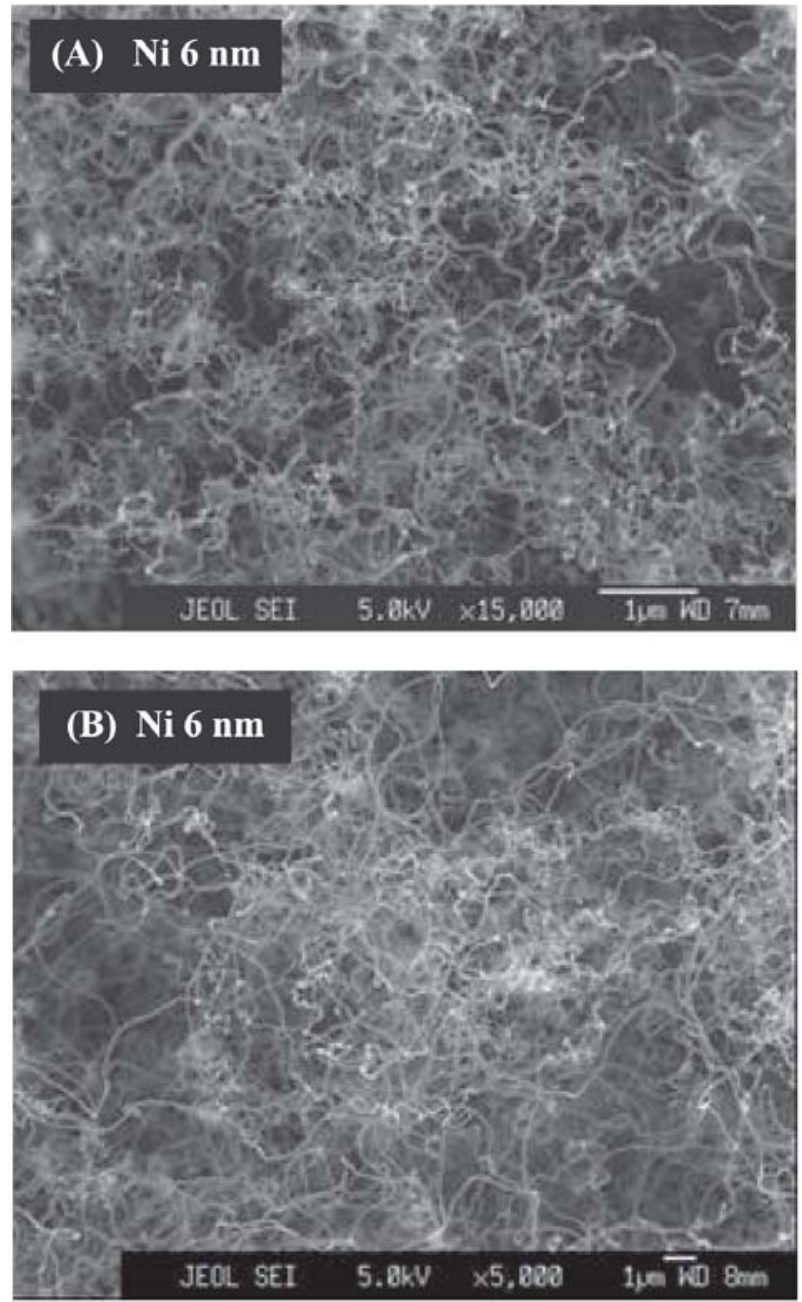

sensitive to variations of the metal catalytic capacity, thus resulting in more uniform CNT growth in all regions of the substrate, as compared with methane. Note that in the growth method $1, \mathrm{a} \mathrm{NH}_{3}$ flow is used in the beginning of the growth process to prevent a possible poisoning of the metal catalyst. As already shown elsewhere for nickel films, ${ }^{18}$ the lack of this step frequently results in encapsulation of catalyst metal particles by an amorphous carbon layer, which hinders nanotubes growth due to loss of the metal catalytic activity. In the growth methods 3 and 4 , this procedure was not necessary because the higher acetylene reactivity promotes faster nucleation and growth of carbon nanotubes so that the catalyst poisoning does not occur. SEM images of $\mathrm{Cu}$ films samples (Figures 5 $\mathrm{C}$ and D) also show that the CNT density increases with temperature and acetylene concentration (growth method 3) similarly to that observed for the growth method 1. As copper is not a magnetic material (in contrast to nickel), the growth method 3 is an interesting
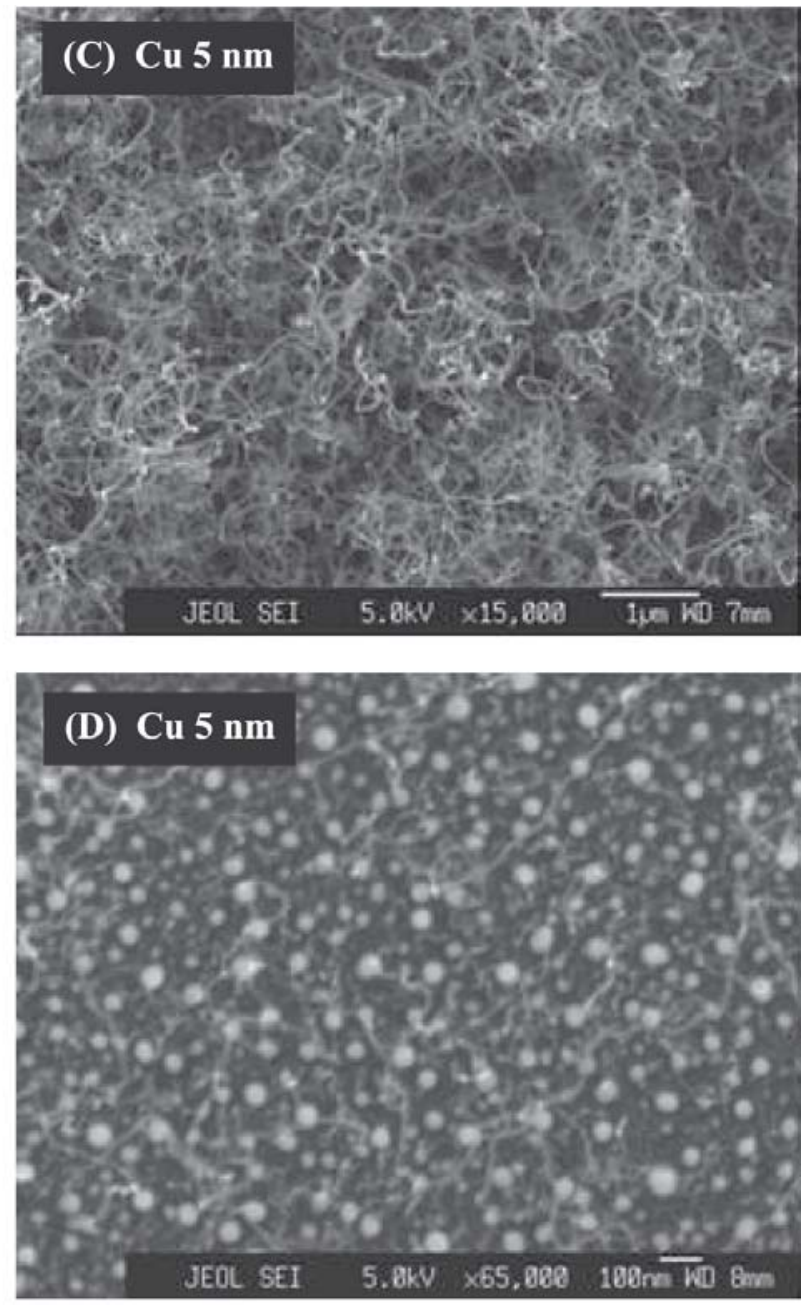

Figure 5. SEM images of carbon nanotubes prepared by growth method 3 (A and C) and growth method 4 (B and D). 

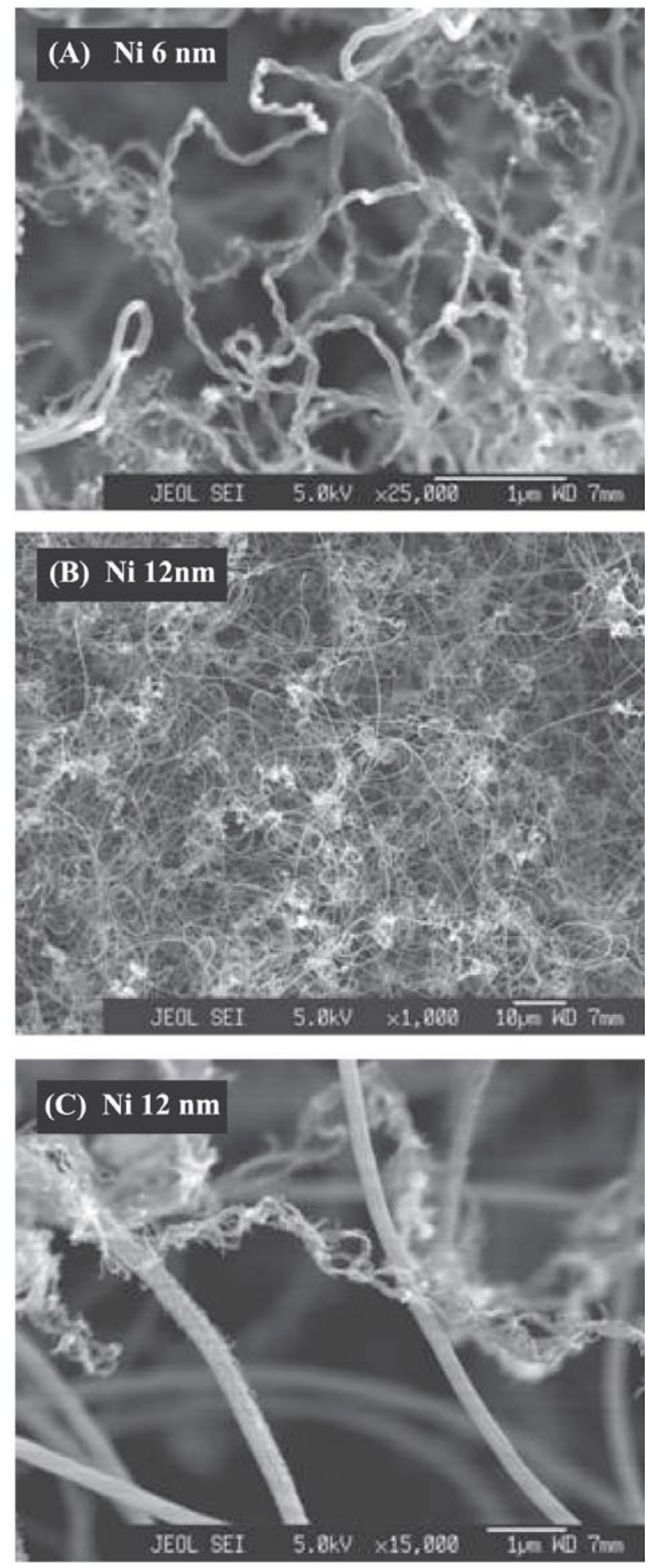

Figure 6. SEM images of samples prepared by growth method 4 using Ni films with different thicknesses.

option for preparation of carbon nanotubes free of magnetic impurities without purification steps.

An unexpected result was observed when partially oxidized Ni films were employed in the growth methods 3 and 4. Deposited Ni films were at least partially oxidized when kept in air more than 3-6 weeks before the CNT synthesis. Figure 6 shows SEM images for samples prepared by the growth method 4 using partially oxidized Ni films with two different thicknesses: 6 and $12 \mathrm{~nm}$. In the case of a $6 \mathrm{~nm}$ thick Ni film (Figure $6 \mathrm{~A}$ ), carbon nanotubes with approximately $70 \mathrm{~nm}$ in diameter were formed together with some fraction of twisted (contortioned) nanofibers. For $12 \mathrm{~nm}$ thick Ni film (Figures $6 \mathrm{~B}$ and C), carbonaceous fibriles were formed jointly with carbon fibers with diameters from 200 to $300 \mathrm{~nm}$ and lengths of dozens of microns.

The growth performed by the method 3 (under the higher temperature and carbon concentration conditions) using the partially oxidized $\mathrm{Ni}$ films led to the growth of carbon nanosprings or nanocoils (Figure 7). Figures $7 \mathrm{~A}$ and $\mathrm{B}$ show the carbon nanostructures formed using the $6 \mathrm{~nm}$ thick Ni film. Carbon nanosprings longer then $10 \mu \mathrm{m}$ with diameter about $150 \mathrm{~nm}$ were grown. When a $12 \mathrm{~nm}$ thick Ni film (Figures $7 \mathrm{C}$ and D) was used, it was also possible to observe extremely long carbon nanosprings with lengths of dozens of microns and diameters in the range of 150-250 nm besides carbon fibers in some cases as long as $\sim 0.1 \mathrm{~mm}$ and with diameters from 150 to $300 \mathrm{~nm}$.

It is likely that the morphological characteristics of the carbon nanomaterials depend essentially on the catalyst features. ${ }^{8,10,19}$ Moreover, the existence of impurities in the metal catalyst was shown to promote a spiral conformation in carbon nanoestructured materials. ${ }^{8,10}$ Therefore, it is very likely that the oxidation of the nickel film was responsible for the nanospring formation in the present study.

An unusual carbon nanostructure was observed in experiments with reduced carbon supply. Experiments performed according to the growth method 2 resulted in formation of rarely observed carbon nanostructures called octopus-like carbon or carbon nanooctopus when copper was used as a catalyst (Figure 8). This carbon nanostructure was first observed in 80's and since then reported in a few studies. ${ }^{12,19}$ Its formation is usually attributed to a specific catalyst composition. Tavares et al. ${ }^{12}$ Bernardo et al. ${ }^{19}$ and $\mathrm{Li}$ et al. ${ }^{12}$ showed that methane decomposition over $\mathrm{Ni} / \mathrm{Cu}$ alloy particles containing more than $10 \%$ copper promoted the growth of at least six carbon filaments originated from a single catalyst particle. A similar phenomenon of branched or multidirectional growth was observed by: (i) RostrupNielsen for nickel catalyst containing high sulphur coverage ${ }^{20}$ (ii) Chambers et al. ${ }^{12}$ for $\mathrm{Co} / \mathrm{Cu}$ alloy particles containing more than 25\% copper, Ermakova et al. ${ }^{13}$ for Fe particles as a catalyst, and Saito ${ }^{13}$ for Ni- 

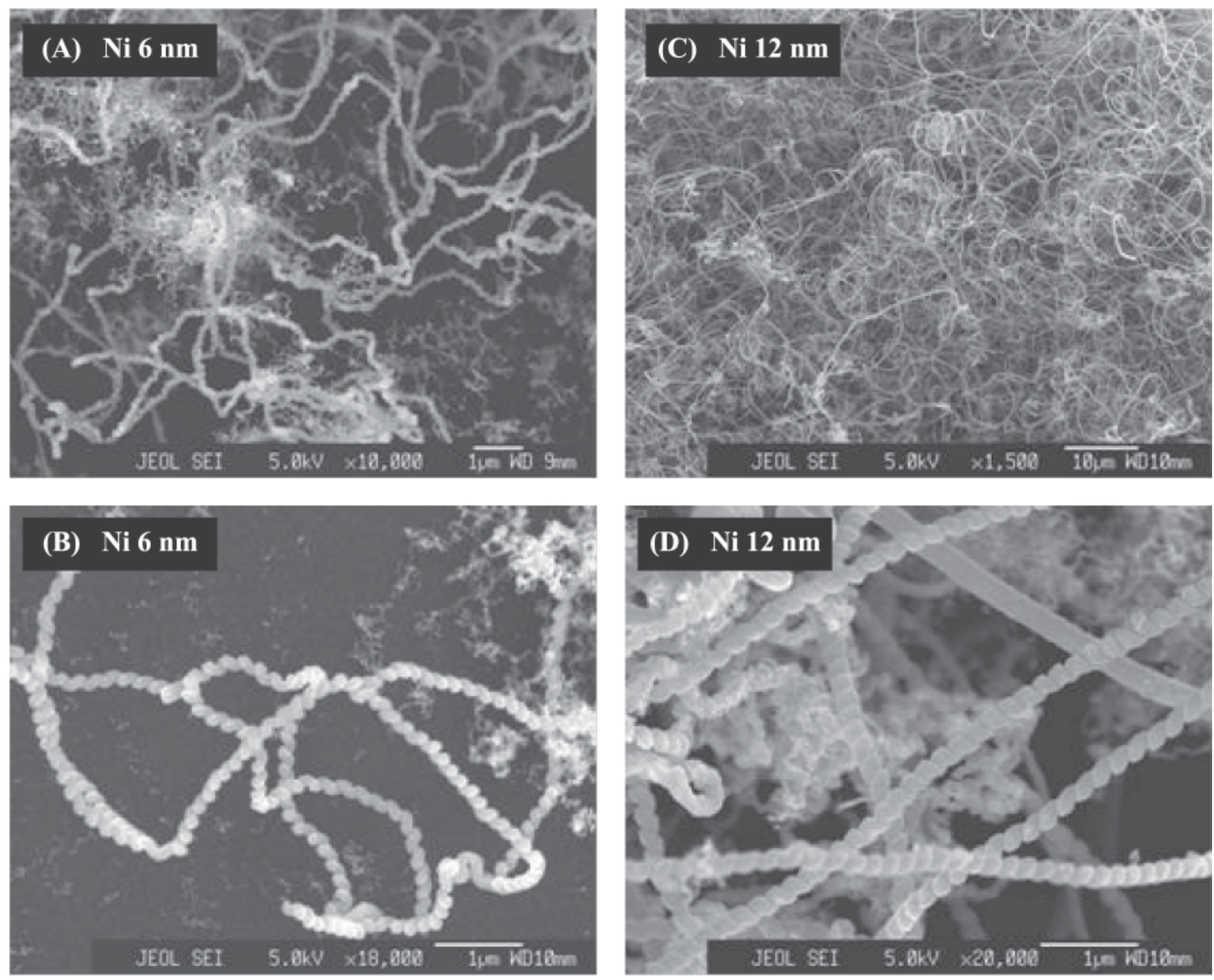

Figure 7. SEM images of samples prepared by growth method 3 using Ni films with different thicknesses.
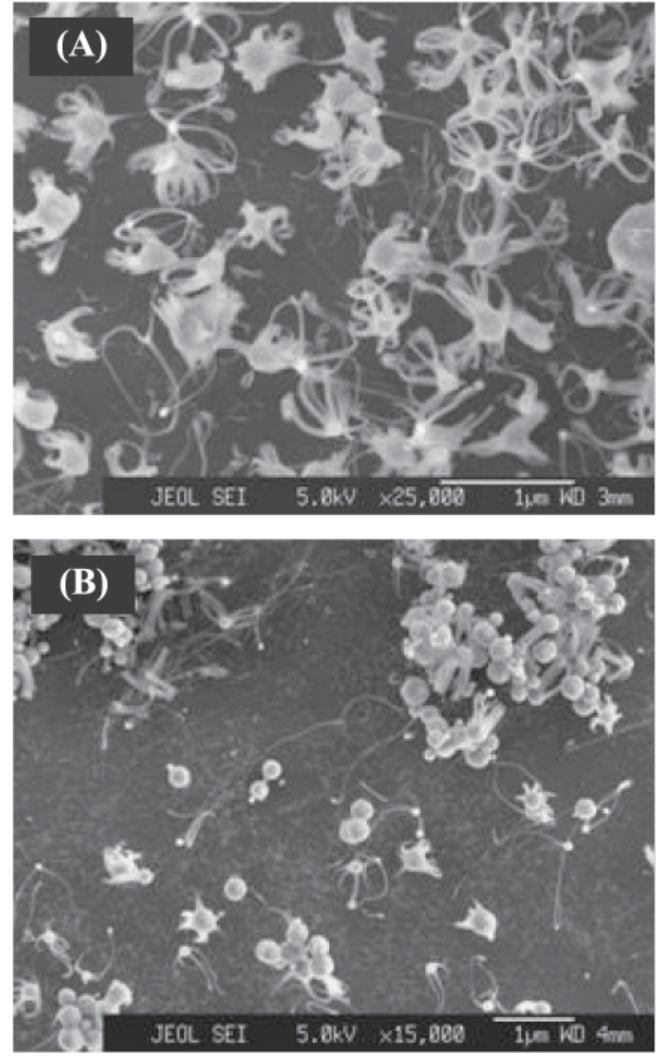

Figure 8. SEM images of samples prepared by growth method 2 using $\mathrm{Cu}$ films with different thicknesses: (A) $20 \mathrm{~nm}$ and (B) $5 \mathrm{~nm}$. carbide particles. The use of carbon precursor gases characterized by relatively low reactivity, as methane, and a limited carbon supply condition seems to be essential for the occurrence of this multidirectional growth. ${ }^{12,13,19}$ To our knowledge, this is the first observation of octopus-like carbon structures formation catalysed by pure copper. This observation was only possible under conditions of a very low carbon supply. The same catalyst used with higher methane (or acetylene) flows led to a conventional nanotubes or nanofibers growth. As the low carbon supply and high temperature were critical conditions for the octopus growth, it is reasonable to suppose that the process is relatively slow and involves a number of isolated catalytic sites (or even groups of smaller sites) on a particle surface where the growth process starts and continues independently, resulting in formation of fibriles or fibrile bundles.

\section{Conclusions}

In the thermal chemical vapor deposition method studied here, the growth of carbon nanostructured materials is shown to be very sensitive to the experimental conditions. For example, apparently small 
changes in the catalyst composition (partial oxidation) can cause dramatic changes in the structure of grown nanocarbon material. A specific combination of different growth parameters has to be found to obtain the desired final material. It has been observed that catalytic properties of the metals used $(\mathrm{Ni}$ and $\mathrm{Cu}$ ) depend essentially on the carbon precursor gas, its partial pressure and the growth temperature. It has been shown that dilution of the carbon feedstock gas (low carbon supply condition) can change the growth mechanisms giving rise to synthesis of unusual nanostructures. In this work, multiwall carbon nanotubes presenting different characteristics, such as length and graphitization degree, were synthesized by combining different experimental parameters of the CVD process. We were also able to obtain different carbon nanostructures such as nanosprings and nanooctopus employing appropriate conditions. Moreover, this work shows for the first time carbon nanostructured materials grown using pure copper as metal catalyst. Usually, literature reports the inability of copper as catalyst for carbon nanostructures synthesis except when it is employed along with another metal forming an alloy. In contradiction, our results show that under appropriate experimental conditions copper can catalyze the conversion of carbon precursors into different nanostructured materials.

In summary, our research activities comprise several topics in the field of the carbon nanostructured materials, such as growth of carbon nanostructures, measurements of their characteristics and fabrication of nanodevices. The initial phase of the research is concentrated on the study of growth mechanisms in order to obtain better control of the synthesis of various carbon nanostructures. This is a problem still far from being solved. Moreover, our interest in fabrication of nanodevices employing carbon nanostructures drives our work beyond the carbon nanotubes, since novel forms of nanostructured carbon materials can also be very promising for future applications.

\section{Acknowledgments}

The work was financially supported by CNPq, Instituto do Milênio SCMN/NAMITEC and IMMC. The authors would like to thank LNLS - National Synchrotron Light Laboratory, Brazil - for GIXRD measurements; LME/LNLS, Campinas, Brazil, for the use of scanning electron microscope; LMF/LNLS, Campinas, Brazil, for the metal $\mathrm{Cu}$ films deposition using sputtering technique and LEM/USP, São Paulo, Brazil, for the use of Raman spectrometer.

\section{References}

1. Sinnott, S. B.; Andrews, R.; Crit. Rev. Solid State Mater. Sci. 2001, 26, 145; Terrones, M.; Int. Mater. Rev. 2004, 49, 325; Dresselhaus, M. S.; Dresselhaus, G.; Charlier, J. C.; Hernandez, E.; Philos. Trans. R. Soc. - Math. Phys. Ang. Sci. A 2004, 362, 2065.

2. Wind, S. J.; Appenzeller, J.; Martel, R.; Derycke, V.; Avouris, P.; J. Vac. Sci. Technol., B 2002, 20, 2798; Kreupl, F.; Graham, A. P.; Duesberg, G. S.; Steinhögl, W.; Liebau, M.; Unger, E.; Hönlein, W.; Microelectron. Eng. 2002, 64, 399; Duesberg, G. S.; Graham, A. P.; Kreupl, F.; Liebau, M.; Seidel, R.; Unger, E.; Hoenlein, W.; Diamond Relat. Mater. 2004, 13, 354; Graham, A. P.; Duesberg, G. S.; Seidel, R.; Liebau, M.; Unger, E.; Kreupl, F.; Hönlein, W.; Diamond Relat. Mater. 2004, 13, 1296.

3. Huh, Y.; Lee, J. Y.; Cheon, J.; Hong, Y. K.; Koo, J. Y.; Lee, T. J.; Lee, C. J.; J. Mater. Chem. 2003, 13, 2297.

4. Chhowalla, M.; Teo, K. B. K.; Ducati, C.; Rupesinghe, N. L.; Amaratunga, G. A. J.; Ferrari, C.; Roy, D.; Robertson, J.; Milne, W. I.; J. Appl. Phys. 2001, 90, 5308.

5. Makris, Th. D.; Giorgi, R.; Lisi, N.; Pilloni, L.; Salernitano, E.; Sarto, F.; Alvisi, M.; Diamond Relat. Mater. 2004, 13, 305.

6. Moshkalyov, S. A.; Moreau, A. L. D.; Guttiérrez, H. R.; Cotta, M. A.; Swart, J. W.; Mater. Sci. Eng., B 2004, 112, 147.

7. Huang, S.; Dai, L.; J. Nanopart. Res. 2002, 4, 145.

8. Kim, M. S.; Rodriguez, N. M.; Baker, R. T. K.; J. Catal. 1992, 134, 253; Luo, T.; Liu, J.; Chen, L.; Zeng, S.; Qian, Y.; Carbon 2005, 43, 755 .

9. Ugarte, D.; Carbon 1995, 33, 989; Miao, J.-Y.; Hwang, D. W.; Narasimhulu, K. V.; Lin, P.-I; Chen, Y.-T.; Lin, S.-H.; Hwang, L.-P.; Carbon 2004, 42, 813.

10. Amelinckx, S.; Zhang, X. B.; Bernaerts, D.; Zhang, X. F.; Ivanov, V.; Nagy, J. B.; Science 1994, 265, 635; Yang, S.; Chen, X.; Motojima, S.; Ichihara, M.; Carbon 2005, 43, 827; Yang, S.; Chen, X.; Kusunoki, M.; Yamamoto, K.; Iwanaga, H.; Motojima, S.; Carbon 2005, 43, 916.

11. Chen, X.; Zhang, S.; Dikin, D. A.; Ding, W.; Ruoff, R. S.; Nano Lett. 2003, 3, 1299.

12. Tavares, M. T.; Bernardo, C. A.; Alstrup, I.; Rostrup-Nielsen, J. R.; J. Catal. 1986, 100, 545; Chambers, A.; Rodriguez, N. M.; Baker, R. T. K.; J. Mater. Res. 1996, 11, 430; Li, J.; Lu, G.; Li, K.; Wang, W.; J. Mol. Catal. A: Chem. 2004, 221, 105.

13. Saito, Y.; Carbon 1995, 33, 979; Ermakova, M. A.; Ermakov, D. Y.; Chuvilin, A. L.; Kuvshinov, G. G.; J. Catal. 2001, 201, 183.

14. Helveg, S.; López-Cartes, C.; Sehested, J.; Hansen, P. L.; Clausen, B. S.; Rostrup-Nielsen, J. R.; Abild-Pedersen, F.; Nørskov, J. K.; Nature 2004, 427, 426.

15. Yousuf, M.; Sahu, P. C.; Jajoo, H. K.; Rajagopalan, S.; Govinda Rajan, K.; J. Phys. F 1986, 16, 373; JCPDS-International Centre for Diffraction Data, PCPDFWIN v. 1.30, 1997. 
16. Dymont, V. P.; Samtsov, M. P.; Nekrashevich, E. M.; Tech. Phys. 2000, 45, 905; Arcos, T. de los; Garnier, M. G.; Oelhafen, P.; Mathys, D.; Seo, J. W.; Domingo, C.; García-Ramos, J. V.; Sánchez-Cortés, S.; Carbon 2004, 42, 187; Cançado, L. G.; Pimenta, M. A.; Saito, R.; Jorio, A.; Ladeira, L. O.; Grueneis, A.; Souza-Filho, A. G.; Dresselhaus, G.; Dresselhaus, M. S.; Phys. Rev. B 2002, 66, 035415.

17. Siegal, M. P.; Overmyer, D. L.; Kaatz, F. H.; Appl. Phys. Lett. 2004, 84, 5156.

18. Choi, G. S.; Cho, Y. S.; Hong, S. Y.; Park, J. B.; Son, K. H.; Kim, D. J.; J. Appl. Phys. 2002, 91, 3847; Jang, Y.-T.; Ahn, J.-
H.; Lee, Y.-H.; Ju, B.-K.; Chem. Phys. Lett. 2003, 372, 745; Juanga, Z. Y.; Chienb, I. P.; Laib, J. F.; Laib, T. S.; Tsaia, C. H.; Diamond Relat. Mater. 2004, 13, 1203.

19. Bernardo, C. A.; Alstrup, I.; Rostrup-Nielsen, J. R.; J. Catal. 1985, 96, 517.

20. Rostrup-Nielsen, J. R.; J. Catal. 1984, 85, 31.

Received: January 23, 2006 Published on the web: August 1, 2006

FAPESP helped in meeting the publication costs of this article. 